\title{
Central Retinal Artery Occlusion Associated with Varicella Dermatitis
}

\author{
Agarwal L ${ }^{1}$, Agrawal N², Labh RK ${ }^{3}$, Choubey R ${ }^{4}$, Agrawal $\mathrm{B}^{5}$
}

${ }^{1}$ Dr. Lalit Agarwal T, Consultant and Head Vitreo-Retina, ${ }^{2} \mathrm{Dr}$. Nisha Agrawal, Consultant Ophthalmologist, ${ }^{3} \mathrm{Dr}$. Rajan Kumar Labh, Paediatric Ophthalmologist, ${ }^{4} \mathrm{Dr}$. Rahul Choubey, Consultant Ophthalmologist. All from the Biratnagar Eye Hospital. ${ }^{5} \mathrm{Dr}$. Bimal Agrawal, Consutant Paediatrician, Koshi Zonal Hospital, Biratnagar, Nepal.

\section{Address for correspondence:}

Dr. Lalit Agarwal T

Head, Department of Vitreo retina

Biratnagar Eye Hospital

Atithi Marg, Rani, Biratnagar-17, Nepal.

Ph- 9852027817

Fax- 021436359

Email-doc_lalit1@yahoo.com

\section{How to cite}

Agarwal L, Agrawal N, Labh RK, Choubey R, Agrawal B. Central Retinal Artery Occlusion Associated with Varicella Dermatitis. J Nepal Paediatr Soc 2016;36(1):78-81.

doi: http://dx.doi.org/10.3126/jnps.v36i1.14876

This work is licensed under a Creative Commons Attribution 3.0 License.

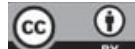

\begin{abstract}
A 12 year girl presented with left eye (LE) loss of vision for four days. Fundus examination and fluorescence angiography revealed LE central retinal artery occlusion (CRAO). She had multiple rashes all over the body. IgM-Varicella antibody assay corresponded with varicella infection and she was diagnosed with CRAO associated with varicella dermatitis.
\end{abstract}

\section{Introduction}

$\mathrm{H}^{\mathrm{s}}$ erpes zoster, caused by varicella-zoster virus (VZV) is usually a benign self-limited disease ${ }^{1}$. It is one of the most common infectious diseases in United States ${ }^{2}$. Usually children between one and nine years of age are affected ${ }^{3}$. Primary infection with this virus leads to generalized varicella dermatitis (chickenpox). It is often followed by chronic pain (postherpetic neuralgia), as well as vasculopathy, myelopathy, retinal necrosis, and cerebellitis ${ }^{4}$. It usually affects small and medium sized arteries ${ }^{4}$. Ocular manifestations occur when the ophthalmic division of the trigeminal nerve is affected ${ }^{1}$, mostly involving the anterior segment which resolves without permanent visual sequelae ${ }^{5}$. Rarely, severe posterior segment manifestation in the form of optic neuritis and retinitis may develop ${ }^{1}$.

We present a patient with near total monocular visual loss following varicella dermatitis.

\section{The Case}

A 12-year-old girl complained of sudden painless loss of vision in her left eye for four days. On questioning, she gave history of fever and multiple rashes all over body for five days prior to onset of ocular symptoms. She was diagnosed as varicella and managed in a local clinic with oral acyclovir. There was no history of similar rash, bleeding or clotting disorder, recent blood transfusion, anti- koch treatment, any persistent drug use in the past or similar illness in any family members. Child had received vaccine as per National immunisation program. There was no history of varicella vaccination in past.

On ocular examination, visual acuity was 6/6 in right eye (RE) and 1/60 in left eye (LE). Anterior segment slit lamp examination was uneventful. There was presence of relative afferent pupillary defect (RAPD) in left eye. Applanation tension was $14 \mathrm{mmHg}$ in each. 
Fundoscopy revealed normal retina in RE and marked retinal edema with cherry-red spot in the LE (Figure $1 \mathrm{~A}, 1 \mathrm{~B})$. Fluorescein angiography (LE) demonstrated delayed arteriolar filling at 179 seconds suggestive of central retinal artery occlusion with involvement of cilioretinal artery as well.

Paediatrician consultation was done and systemic examination was normal except for the rash (Figure $1 C)$ that was in different stages of development from vesicles, pustules to eschar.

Routine blood examination including clotting profile, complete blood counts, fasting blood glucose, lipids, and urinalysis were normal. Serological studies for HIV, HBsAg, TORCH and TB were negative. There was neutrophilia (75\%) and erythrocyte sedimentation rate $(60 \mathrm{~mm} / \mathrm{hr}$ ) was raised. Immunoglobulins for varicella were markedly increased when tested at the time of presentation $(\lg G=0.6 \mathrm{IU}, \lg M=11.2 \mathrm{IU}$, reference normal value $<0.8 \mathrm{IU})$.

Treatment was attempted with oral acetazolamide $250 \mathrm{mg}$ thrice daily for 3days and oral acyclovir $800 \mathrm{mg}$ five times a day for 7 days without success.

The retinal oedema decreased over the subsequent three months period but the appearance of arterioles remained the same (Figure 1D). The optic disc became pale and atrophic. Her visual acuity did not improve even at final follow-up.

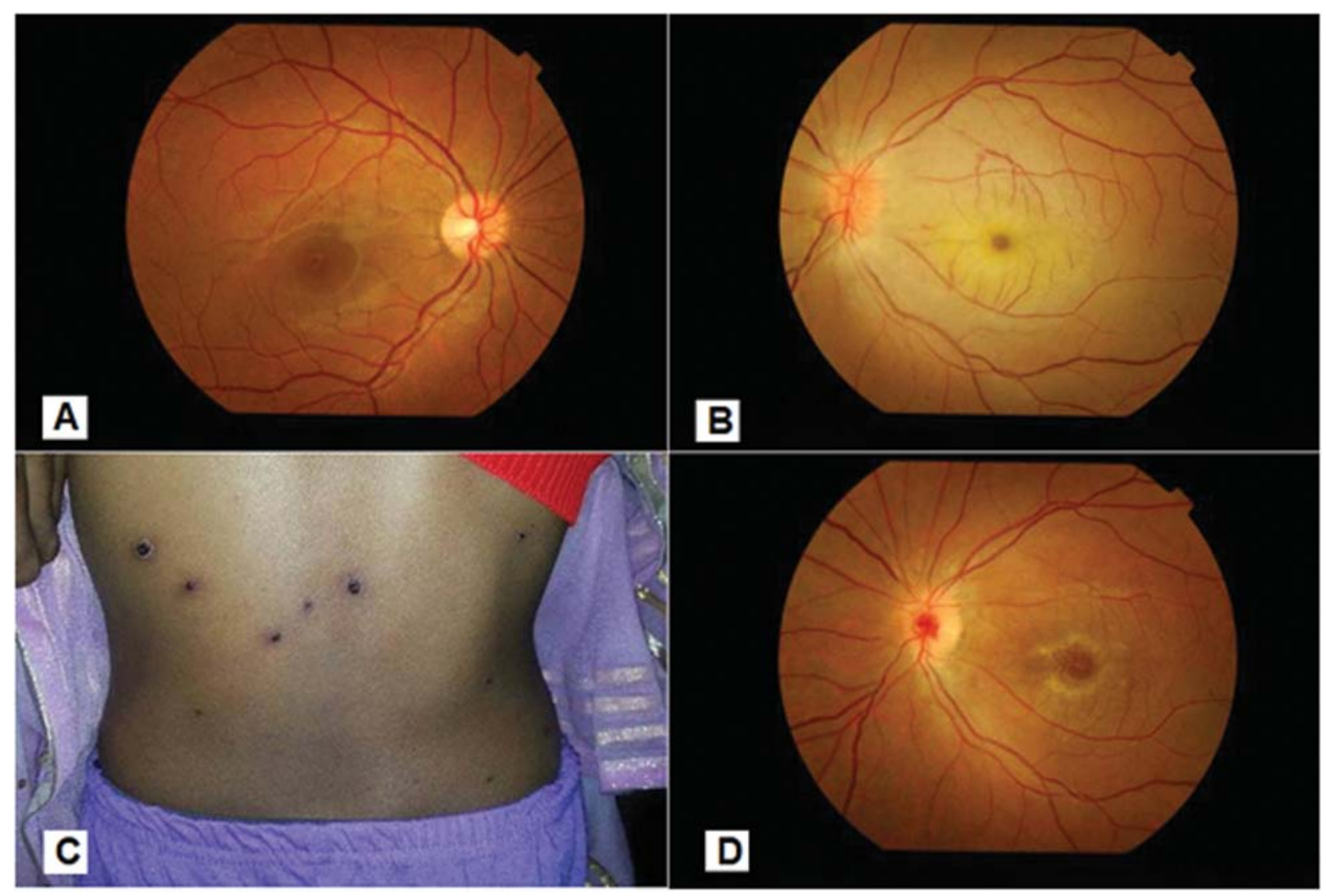

Fig 1: Colour fundus photo and skin lesions. (A) Normal fundus photo of right eye. (B) Marked retinal edema with cherryred spot in left eye at presentation. (C) Multiple skin lesions in the stage of scab formation. (D) Resolved retinal oedema with optic atrophy and pigmented macula in left eye at three month follow-up. 


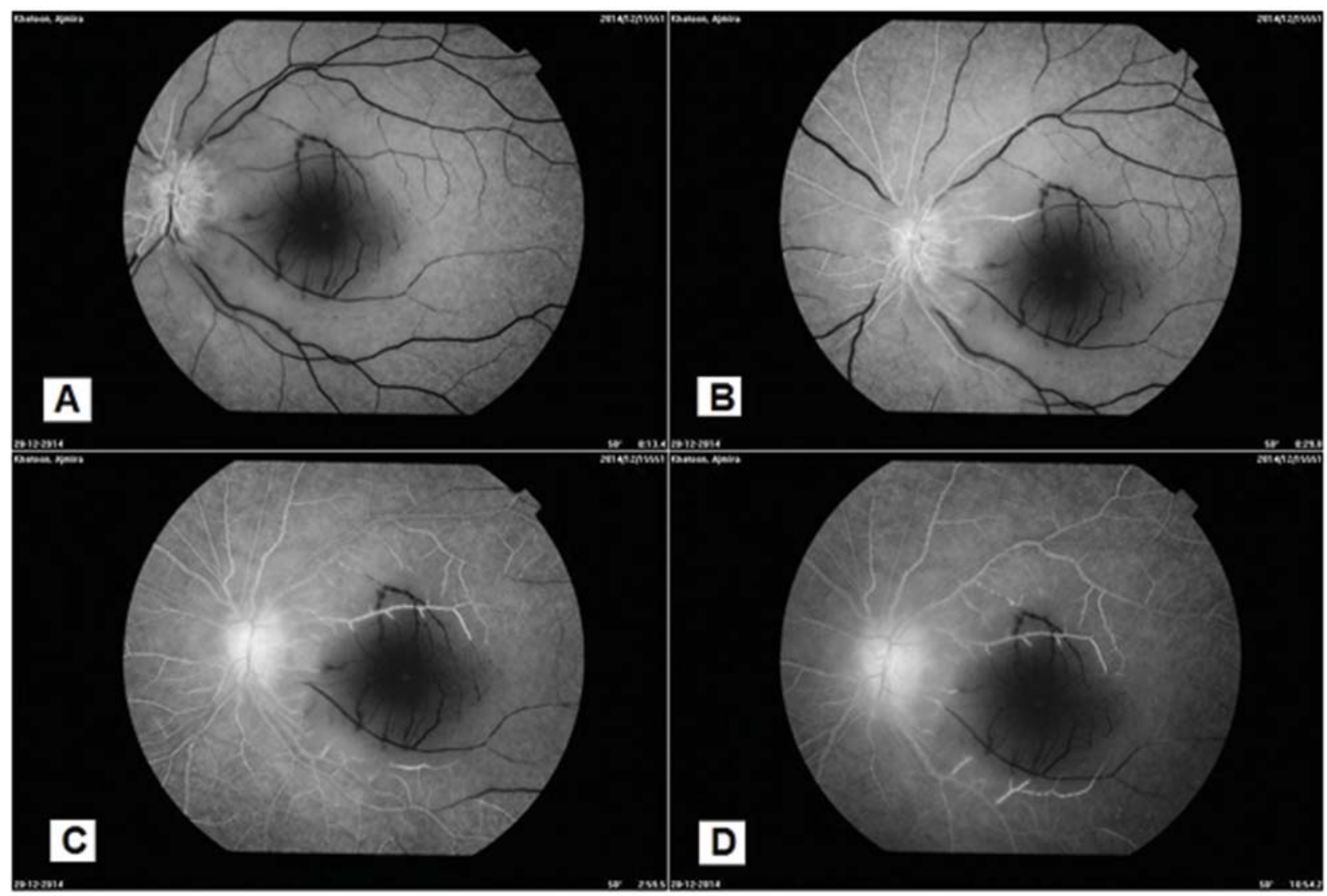

Fig 2: Fundus fluorescein angiography (FFA) showing beginning of arterial filling at 14 seconds (A) delayed arterial filling at 29 and 179 seconds (B\&C) and late staining of disc (D).

\section{Discussion}

We presented a patient with LE CRAO post varicella dermatitis.

The most common cause of CRAO is embolic obstruction, with carotid artery being the commonest source of endogenous emboli. Other mechanisms include exogenous emboli, thrombotic, vasospastic and vasculitic events.

Serious complications following chicken-pox are fortunately rare $^{6}$ and the published reports of visual disturbances occurring with it are few ${ }^{7}$. However, in rare instance, chickenpox may be complicated by involvement of posterior segment of the eye resulting in visual disturbance, irrespective of the immunologic status or age of the individual.

Similar case of monocular vision loss due to CRAO associated with chickenpox has been reported by various authors ${ }^{2,8,9}$. Similar to our case, all of these case reports manifested after five days of history of exanthema. VZV association with Branch retinal artery occlusion has also been reported by Hugkulstone CE et $\mathrm{al}^{10}$. In contrary to these cases, very recently a bilateral ophthalmic artery occlusion in association with VZV infection was described by Jayram $\mathrm{H}$ et al ${ }^{11}$. These cases are rare in occurrence and have been reported sparsely.

Literature highlights some reports of occurrence of papilitis, retinitis and phlebitis $3,5,12,13,14,15,16$. However, our patient did not manifest with any of these findings.

Many complications of varicella- zoster infections in adults may have an ischemic basis ${ }^{17}$, a retinal vasculitis or perivasculitis, or a granulomatous angiitis affecting the brain ${ }^{18}$. The exact cause of the central retinal artery occlusion in our patient is not known, but an arterial vasculitis analogous to that seen in adults with varicellazoster retinitis may be the cause ${ }^{19}$.

Age at ocular involvement may vary. Our patient was a 12 years old girl. Mark et $\mathrm{al}^{2}$ and $\mathrm{Cho} \mathrm{N}$ et $\mathrm{al}^{6}$ also reported similar illness in younger aged children, five years and eight years respectively. Whereas $\mathrm{Kim} \mathrm{SH}$ et al ${ }^{9}$ reported it in an elder patient of 24 years. Patient with bilateral involvement was a six years old boy ${ }^{11}$.

Patients have been treated with intravenous acyclovir in the past, the benefit of which is controversial. In the case report by Mark et al, the child was treated 
with immediate anterior chamber (AC) paracentesis followed by a week's course of intravenous acyclovir without any visual gain². There was no improvement in visual acuity after treatment with $\mathrm{AC}$ paracentesis and intravenous acetazolamide in the case reported by Cho $\mathrm{N}$ et $\mathrm{al}^{8}$

Jayram $\mathrm{H}$ et al reported no improvement with intravenous acyclovir and methylprednisolone ${ }^{12}$. Adding oral steroid to oral acyclovir also has poor visual outcome ${ }^{20}$. Similarly, our patient also did not respond to treatment with oral acyclovir and acetazolamide.

\section{Conclusion}

Para-infectious vasculitis and angiitis following viral illness may be the cause of CRAO secondary to Varicella-Zoster infection in our patient. Children suffering from chickenpox and with ocular symptoms like congestion, blurred vision should immediately be subjected to an ophthalmological examination, irrespective of their immunologic status. Whether early diagnosis and prompt treatment can preserve some residual visual function remains a matter of debate.

\section{References}

1. Ostler HB, Thygeson P. Ocular manifestation of herpes zoster, varicella, infectious mononucleosis and cytomegalovirus disease. Surv Ophthalmol 1976;21(2):148-59.

2. Mark AF, Anthony JM. Monocular Blindness From Central Retinal Artery Occlusion Associated With Chickenpox. Am J Ophthalmol 1994;117(1):117-18.

3. Tappeine C, Aebi C, Garweg JG. Retinitis and optic neuritis in a child with chickenpox: case report and review of literature. The Pediatr Infect Dis $J$ 2010;29(12).

4. Gilden D, Cohrs RJ, Mahalingam R and Nagel MA. Varicella zoster virus vasculopathies: diverse clinical manifestations, laboratory features, pathogenesis, and treatment. Lancet neurol 2009; 8(8):731.

5. Purvin V, Hrisomalos N, Dunn D. Varicella optic neuritis. Neurology 1988; 38:501.

6. Macleod J, ed. Davidson's principles and practice of medicine. Edinburgh: Churchill Livingstone, 1984: 730.

7. Duke-Elder S. System of ophthalmology. London: Kimpton. 1976; 15: 167.

8. Cho N, Han H. Central Retinal Artery Occlusion After Varicella. Am. J. Ophthalmol 1992;113:591-2

9. Kim SH, Yun YJ and Kim JY. Central Retinal Artery Occlusion Associated with Chickenpox. J Korean Ophthalmol Soc. 2008; 49(5):853-57.

10. Hugkulstone CE, Watt LL. Branch retinal artery occlusion with chicken-pox. British J Ophthal 1988; 72(1):78-80.
11. Capone A, Meredith TA. Central visual loss caused by chickenpox retinitis in a 2-year old child. Am. J. Ophthalmol 1992; 113: 592-93.

12. Jayaram H, Segal DS, Holder GE, Graham EM. Bilateral Ophthalmic Artery Occlusions Due to Probable Varicella-Zoster Virus Vasculopathy. Arch Ophthalmol. 2012; 130(11):1492-149.

13. Copenhaver M. Chickenpox with retinopathy. Arch Ophthalmol 1966; 75: 199

14. Ford FR. Diseases of the nervous system in infancy, childhood and adolescence. Springfield, Illinois: Thomas, 1966: 576-77.

15. Hatch HA. Bilateral optic neuritis following chickenpox. J Pediatr 1949; 34: 758-9.

16. Liioi JA, Aiello MV. Bilateral papilloedema with chickenpox. J Pediatr Ophthalmol Strabismus 1970; 7: 155.

17. Liesegang TJ. The varicella zoster virus. Systemic and ocular features. J Am Acad Dermatol 1984; 11:165.

18. Blue MC, Rosenblum WI. Granulomatous angiitis of the brain with herpes zoster and varicella encephalitis. Arch Pathol Lab Med 1983; 107:126.

19. Kuo YH, Yip Y, Chen SN. Retinal Vasculitis associated with Chickenpox. Am. J. Ophthalmol 2001;132(4):5845.

20. Murdock J, Carvounis PE. Adult with chickenpox complicated by systemic vasculitis and bilateral retinal vasculitis with retinal vascular occlusions. Retin Cases Brief Rep 2016;0:1-5. 